\title{
Analysis of Forces and Deformation Rule of Existing Shield Tunnel Caused by Ground-heaped Load
}

\author{
Gang Wei ${ }^{1, *}$, Wei-xuan Jin ${ }^{1}$, Cheng-hong Cui ${ }^{2}$ and Qi Ye \\ ${ }^{1}$ Department of Civil Engineering, Zhejiang University City College, Zhejiang, Hangzhou 310015, China \\ ${ }^{2}$ Department of Civil Engineering and Architecture, Anhui University of Science and Technology, Huainan 232001, China \\ ${ }^{3}$ Pypun Engineering Consultants Ltd., Hong Kong
}

Received 19 January 2017; Accepted 25 April 2017

\begin{abstract}
Ground-heaped load often leads to complex stresses on existing shield tunnels, which can cause deleterious effects, such as cracking and uneven deformation. The mechanical behavior of shield tunnels caused by ground-heaped load was analyzed to examine the influence of ground load on the force and deformation of shield tunnels and reduce and prevent harm to shield tunnels caused by ground load. The mechanism of ground-heaped load that affect shield tunnels was also explored. The internal forces of lining were calculated with and without ground-heaped load and the results of forces were compared using the modified routine method of lining design theory. Finally, the deformation laws of tunnel were examined based on different magnitudes and locations of ground-heaped load by employing 3D software MIDAS/GTS NS. Results show that ground load can lead to the settlement of the tunnel, wherein the maximum settlement increases linearly with increasing ground load. The settlement of tunnels decreases as the distance between the stacking center and the tunnel center increases, whereas horizontal displacement increases before decreasing. The bending moment, axial force, and shear force increased by $69.34 \%, 51.90 \%$, and $67.11 \%$, respectively, compared with those measured without ground-heaped load. The conclusions obtained in this study have an important guiding significance for predicting and controlling the force and deformation of shield tunnel caused by ground-heaped load in practical engineering.
\end{abstract}

Keywords: Shield tunnel, Ground-heaped load, Lining, Deformation

\section{Introduction}

Accidents have frequently occurred in tunnel excavation and operation given the construction of a large number of China's subway tunnels in recent years. During the completion and operation periods, the existing tunnel is often influenced by foundation pit excavation [1], [2], [3], tunnel excavation [4], [5], [6], pile foundation construction [7], [8], [9], and ground-heaped load [10], [11], [12]. Movement and destruction in the adjacent tunnel would occur during excavation of a foundation pit [13], [14]. Many scholars studied the effect of unloading attributed to excavation on existing tunnels by simulating foundation pit excavation using finite element [15], [16], [17].

The cases of damage on existing tunnels caused by ground-heaped load continue to increase, but only a few related studies were conducted. The present study examines the influence of ground-heaped load on existing tunnels. The upper ground-heaped load would cause a negative impact on shield tunnel structures. In addition, existing shield tunnels are sensitive to deformation, which causes significant settlement. Ground-heaped load can also lead to cracks or uneven longitudinal and circumferential deformation in existing shield tunnel structures; these cracks and deformations are likely to cause dislocation of segments, concrete fragmentation [10], [11], [12] near bolt holes, and

\footnotetext{
"E-mail address: weig@zucc.edu.cn

ISSN: $1791-2377$ @ 2017 Eastern Macedonia and Thrace Institute of Technology. All rights reserved. doi:10.25103/jestr.103.08
}

failure of tunnel structures, which cause economic losses and security issues in tunnel operation.

Based on this analysis, the present study examines the mechanism of shield tunneling caused by upper ground load, and compares it with theoretical and finite element numerical calculations. Therefore, accurate prediction and control of internal forces and deformation of shield tunnels caused by ground-heaped load are of great significance. The relevant engineering problems should be urgently resolved.

\section{State of the Art}

At present, research on the influence of ground-heaped load on shield tunnels mainly focuses on theoretical calculation [18], [19], [20], numerical analysis [21], [22], [23], [24], model testing [25], [26], and field measurement [27], [28].

Among the theoretical calculations, Li Chunliang et al. [18] created a longitudinal stress model for a shield tunnel subjected to the effects of ground-heaped load on the basis of elastic foundation beam theory. Their study showed that if the burial depth of tunnels is shallow or the strength of soil is weak, ground-heaped load would result in large settlement, deformation, and internal force. However, this research is limited to the deformation and force of tunnel structures due to ground-heaped load. Mechanism analysis was not conducted.

In terms of numerical analysis, Zhang Yuxu et al. [21] simulated the influence of ground-heaped load on shield tunnels under different loading periods and loading 
magnitudes using finite element method (FEM). Yamamoto et al. [22] and Lyamin et al. [23] created a model with relative smooth boundary condition and studied the stability of circular and dual circular tunnels in cohesive-frictional soils subjected to surcharge loading. Data obtained through FEM were compared with predicted data. It is more intuitive to understanding the internal force and deformation in tunnels by using finite element numerical simulation, but existing research is not comprehensive and only considers the impact of different magnitudes of load.

Atkinson and Pott [25] studied the stability of a tunnel in cohesiveless clay in an indoor model test. In conjunction with the actual conditions of a Shanghai subway project, $\mathrm{Wu}$ Qing et al. [26] studied the deformation characteristics of existing shield tunnel structures under different tunnel burial depths and different loading positions using the indoor model test. The model test can determine the internal force distribution of the lining structure in the tunnel under ground load and can also obtain the deformation laws of the shield tunnel under different conditions. However, the drawback is that the deformation of the tunnel lining cannot be determined.

In terms of field measurement, software is used to analyze and simulate construction given the huge workload and time requirement. Qinhao and Shigang [27] used a three-dimensional numerical method to analyze the deformation of tunnel under ground-heaped load. A tunnel, which crossed the river with an existing ground-heaped load of sand, was located in a buried segment on Donghuan Road. Hong-wei Huang and Dong-ming Zhang [28] established a detailed model to assess the resilience of shield tunnels. Their results were compared with those obtained through a field measurement of Shanghai metro, which assessed the recovery of tunnels under unfavorable conditions. Although these studies were combined with engineering examples, limitation still exists because of the complexity of site conditions. Therefore, detailed studies should be urgently conducted on the effects of ground-heaped load on mechanical properties and deformation of shield tunnels.

To address these deficiencies, the mechanism of groundheaped load and its effects on shield tunnels are first analyzed. Second, the internal forces of the lining are calculated with and without ground-heaped load, respectively, using the modified routine method of lining design theory. The results of the forces are compared. Finally, MIDAS/GTS NX software is used to establish a three-dimensional finite element model. The deformation laws of tunnels are based on different magnitudes and locations of ground-heaped load.

The remaining sections of this study are organized as follows. In the third section, the mechanism of the ground load that affects shield tunnels is analyzed. Theoretical calculation and establishment of the three-dimensional finite element model are adopted. In the fourth section, the mechanism is validated by different cases. The results of the theoretical calculation and FEM are analyzed. The last section summarizes and concludes.

\section{Methodology}

\subsection{Analysis of the influence of ground load on shield} tunnels

In the absence of ground-heaped load, the tunnel is considered in force balance under its own weight and pressure from the surrounding water and soil (see Fig. 1a).
When ground-heaped load is directly above the shield tunnel (symmetrical loading), the balance of forces from soil is broken and leads to settlement of the soil above the tunnel structure, which breaks the force balance in the vertical direction (see Fig. 1b). The additional force from the top of the tunnel leads to settlement of the tunnel. The additional force on the tunnel and longitudinal displacement will increase with increased ground-heaped load under the same condition. On the one hand, longitudinal displacement will likely exceed the safety limit (20 $\mathrm{mm}$ [29]). On the other hand, the horizontal force balance on the tunnel is maintained, subject to less horizontal displacement.

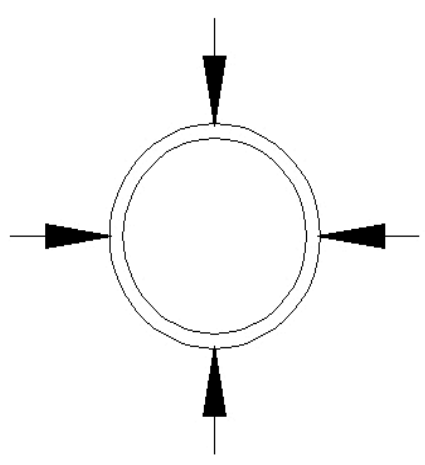

(a) Tunnel in its initial stress state of equilibrium

Ground-heaped load

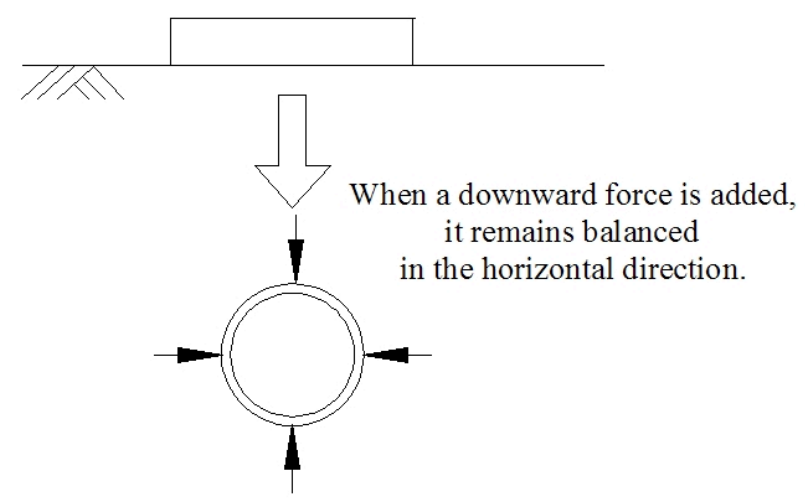

(b) Loading from above breaks the load balance on the tunnel

Fig. 1. Loading directly above the tunnel and its impact on vertical displacement

We denote the thickness of soil cover above the tunnel as $H$, depth of the tunnel axis as $z_{0}$, density of the soil as $\gamma$, and the coefficient of static earth pressure as $K_{0}$. The vertical pressure on the roof of the tunnel is obtained by $\gamma H$ and horizontal pressure on the axis of the tunnel is obtained by $K_{0} \gamma z_{0}$. Before loading of ground-heaped load, the vertical soil pressure on the tunnel roof is usually higher than the horizontal pressure because the coefficient of static earth pressure $K_{0}$ in soft soil is less than 1 . Thus, the tunnel is subject to horizontal tension and vertical compression. Such conditions lead to the deformation of the cross-section into a horizontal ellipse (see Fig. 2a). If ground-heaped load is above a shield tunnel, the vertical pressure on the tunnel increases, whereas horizontal pressure basically remains 
unchanged (balanced force). The situation exacerbates (see Fig. 2b) to a certain extent, such that safety limits on deformation may easily be exceeded.

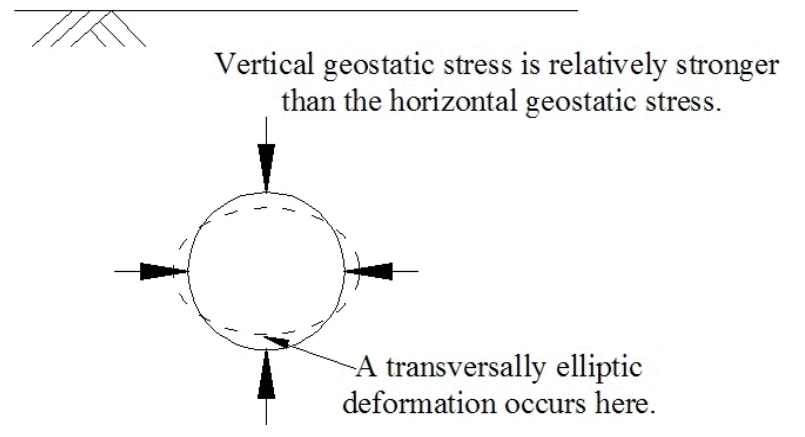

(a) Initial state of tunnel

\section{Ground-heaped load}

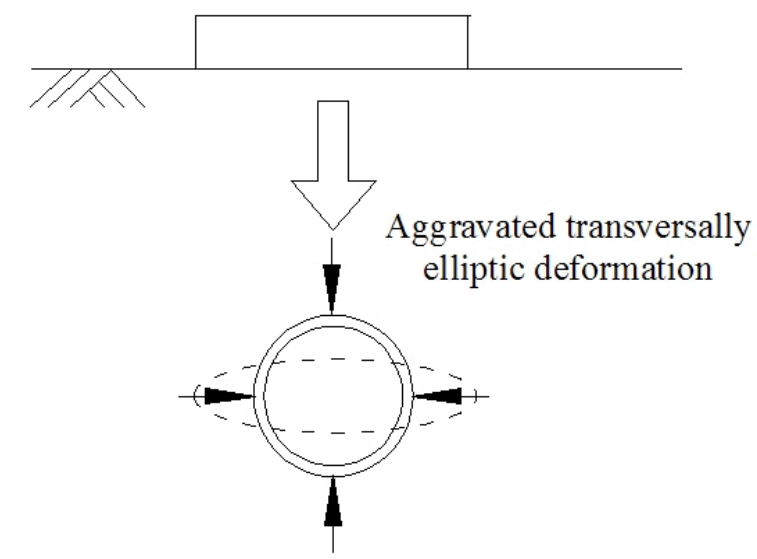

(b) Deformation of the tunnel under direct loading

Fig. 2. Impact of loading on deformation of the tunnel

\section{Ground-heaped load}

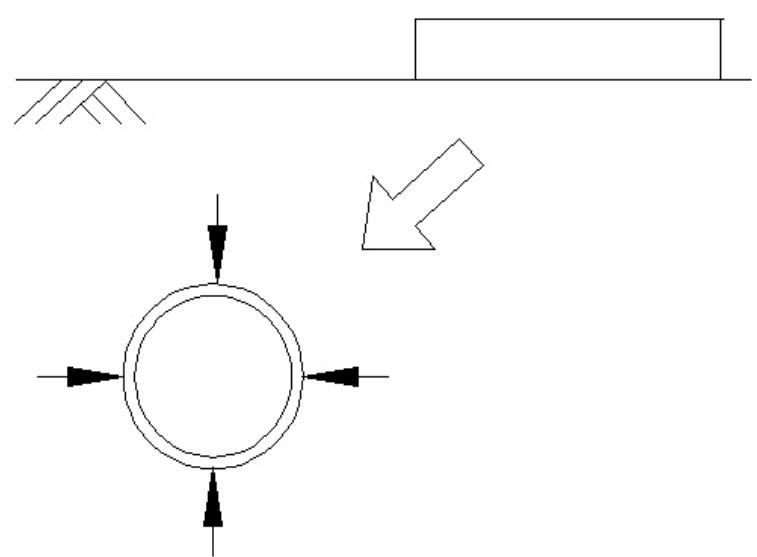

Fig. 3. Upper loading on both sides and their impact on tunnel displacement

When the tunnel is under asymmetric load (positioned above the tunnel but to its left or right), it is subject not only to additional vertical pressure, but also to additional horizontal pressure (see Fig. 3). Horizontal displacement occurs opposite to the ground-heaped load (besides the vertical settlement), which results in complicated deformation.
3.2 Analysis of the mechanical behavior of tunnel linings under ground load

The main computing models for the internal forces of shield tunnel lining design [30] include: (1) experimental analogy, (2) load structure, (3) stratum structure, and (4) convergence limit. The method most commonly used at present in China is a modified routine model (see Fig. 4 [31]), in which $p$ is the ground load, $p_{\mathrm{w} 1}$ is the vertical water pressure, $p_{e 1}$ is the vertical soil pressure, $p_{\mathrm{w} 1}$ is the self-load, $q_{\mathrm{w} 1}$ is the lateral water pressure, $q_{e 1}$ is the lateral soil pressure, and $R_{e}$ is the lining concentric radius. Specific calculation formulas can be found in [32].

The method has been used to analyze the mechanical behavior of tunnel linings under external loads.

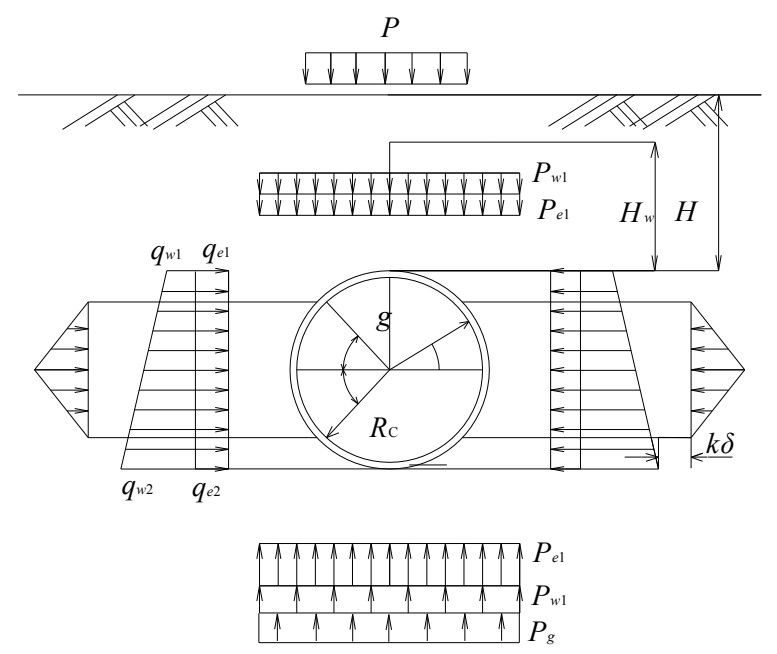

Fig. 4. Modified load distribution model [31]

The following values are assumed: tunnel external diameter $D_{0}=6 \mathrm{~m}$, segment width $B=1 \mathrm{~m}$, segment thickness $h=0.35 \mathrm{~m}$, soil covering thickness $H=9 \mathrm{~m}$, lining elastic modulus $E=33 \mathrm{GPa}$, lining self-load $g=$ $8.75 \mathrm{kPa}$, effective ratio of bending rigidity $\eta=0.8$, moment magnification factor $\xi=0.2$, water table depth $=2 \mathrm{~m}\left(H_{\mathrm{w}}=\right.$ $7 \mathrm{~m}$ ), soil density $\gamma=18 \mathrm{kN} / \mathrm{m}^{3}$, soil effective unit weight $\gamma^{\prime}=8 \mathrm{kN} / \mathrm{m}^{3}$, soil internal friction angle $\varphi=15^{\circ}$, soil cohesion $c=12 \mathrm{kPa}$, coefficient of subgrade reaction $k=5$ $\mathrm{kN} / \mathrm{m}^{3}$, lateral earth pressure coefficient $K_{0}=0.5$, and ground-heaped load $P=100 \mathrm{kPa}$.

We take the tunnel vertex as the starting point $\left(0^{\circ}\right)$ to ensure that the angle between the tunnel vertex and the tunnel bottom is $180^{\circ}$. The moment on the cross-section of the lining, the bending moment and shear and axial force are calculated under standard conditions (without groundheaped load) and under ground-heaped load. The results are then compared.

\subsection{Three-dimensional finite element simulation}

Tunnel models are built by three-dimensional finite element simulation by means of MIDAS/GTS NX software. This model, which assumes homogeneous soil layers, is based on the Mohr-Coulomb model and uses solid elements. The parameters of the soil mass are taken as follows: elasticity modulus $E=18 \mathrm{MPa}$, Poisson's ratio $\mu=0.38, \gamma=18.5$ $\mathrm{kN} / \mathrm{m}^{3}, \varphi=15^{\circ}, c=12 \mathrm{kPa}$, and $K_{0}=0.53$. 
The tunnel was assumed to consist of homogeneous slabs, with a $6 \mathrm{~m}$ outer diameter $\left(D_{0}=6 \mathrm{~m}\right)$ and $0.35 \mathrm{~m}$ thickness. An elastic model was assumed regardless of the presence of joints. To take account of the impact of joints and seams between segments when constructing the tunnel, the modulus of elasticity of the concrete in the tunnel should be lowered by an appropriate amount. The parameters of the tunnel were taken as follows: elasticity modulus $E=30 \mathrm{GPa}$, unit weight $25 \mathrm{kN} / \mathrm{m}^{3}$, and Poisson's ratio $\mu=0.17$.

The entire model was $80 \mathrm{~m}$ wide, $40 \mathrm{~m}$ high, and $120 \mathrm{~m}$ long (in the direction of the tunnel). The soil thickness above the tunnel is $H=9 \mathrm{~m}$. The ground-heaped load is squareshaped with a $20 \mathrm{~m}$ side length. Under standard conditions, the distance between the tunnel axis is $L$, and the medial axis of loading is $0 \mathrm{~m}$ (as shown in Fig. 5) and the groundheaped load $P=100 \mathrm{kPa}$. Adopting automatic meshing, the tunnel consists of 60 tunnel mesh sets (as shown in Fig. 6). Fig. 7 shows the meshing for the entire model.

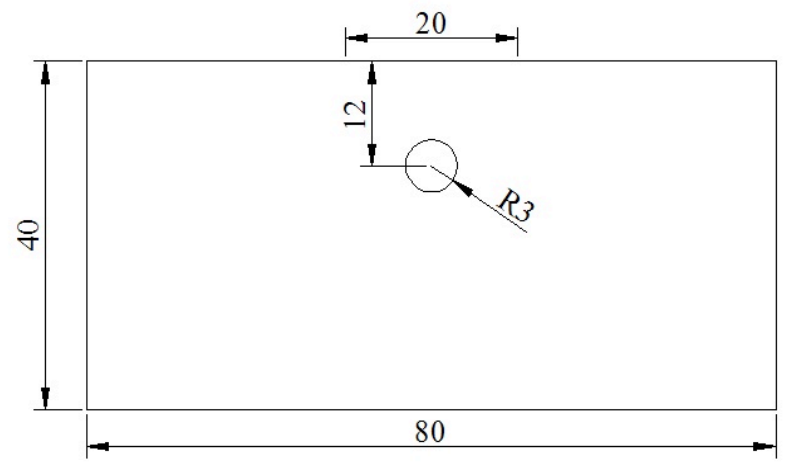

(a) Front view (m)

(b)

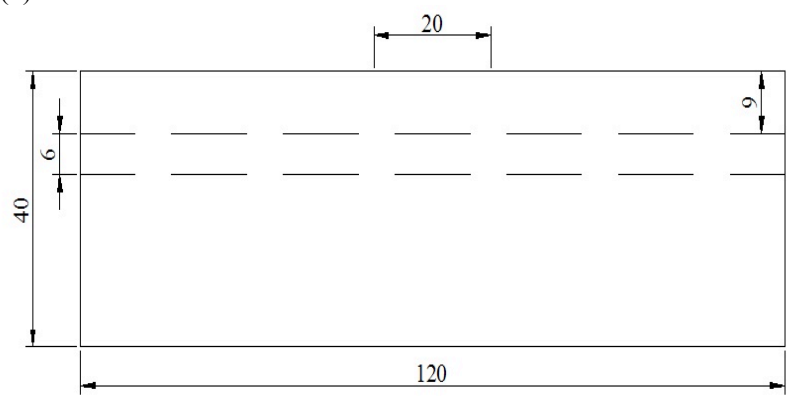

(b) Right view (m)

Fig. 5. Geometry of model under standard condition (lengths in meters)

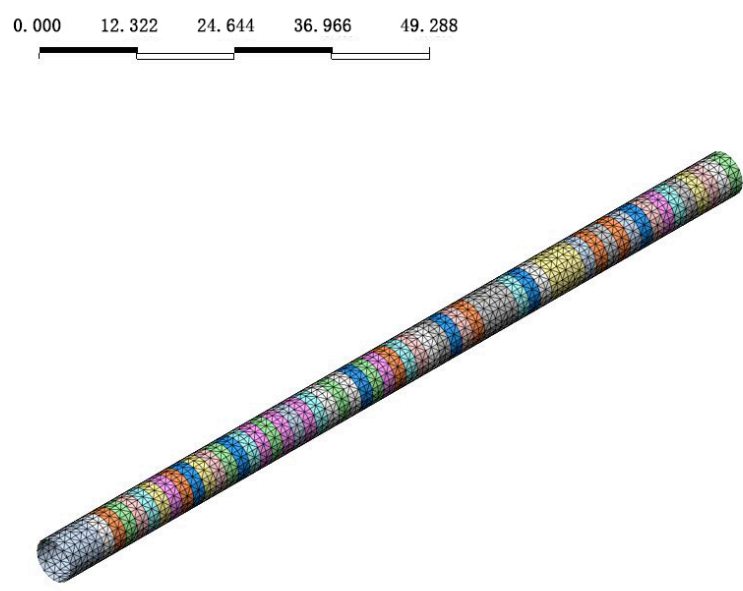

Fig. 6. Meshing of tunnel

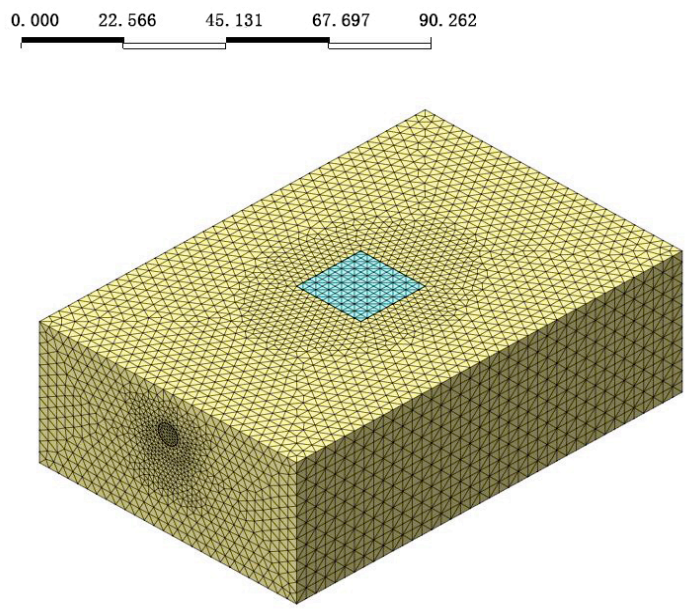

Fig. 7. Meshing of the three-dimensional model as a whole

\section{Result Analysis and Discussion}

\subsection{Verification mechanism}

The results of the mechanism analysis of the influence of shield tunnel by ground loads in Section 3.1 are verified by the data of the project cases.

To test the reliability of the theoretical analysis, data from five tunnel projects subject to loading were considered [19], [27], [33], [34], details are shown in Table 1. Among these data, the first three projects were from field tests, whereas the last two were from three-dimensional finite element analyses. Of the four projects, two involved loads directly above the tunnel and two involved loads on either side of the tunnel.

Table 1. Data for the tunnel projects with loading

\begin{tabular}{|c|c|c|c|c|}
\hline Project name & $\begin{array}{c}\text { Data } \\
\text { collection } \\
\text { approach }\end{array}$ & $\begin{array}{l}\text { Relative position } \\
\text { of loading }\end{array}$ & $\begin{array}{c}\text { Maximum displacement of } \\
\text { tunnel }\end{array}$ & Soil condition \\
\hline $\begin{array}{l}\text { Jungong Road River-crossing } \\
\text { tunnel in Shanghai [33] }\end{array}$ & Field test & $\begin{array}{l}\text { Above and to the } \\
\text { right of tunnel }\end{array}$ & Settlement, $20 \mathrm{~mm}$ & Silty clay, muddy soil and fine sand \\
\hline $\begin{array}{l}\text { Shield tunnel in south China } \\
\text { [34] }\end{array}$ & Field test & $\begin{array}{l}\text { Directly above the } \\
\text { left line of the } \\
\text { tunnel }\end{array}$ & $\begin{array}{l}\text { Settlement on the left, } 22.8 \\
\mathrm{~mm} \text {, settlement on the right, } \\
16.2 \mathrm{~mm}\end{array}$ & $\begin{array}{l}\text { Rigid-plastic metamorphic rocks or } \\
\text { relatively thick residual soil }\end{array}$ \\
\hline $\begin{array}{l}\text { Dong Wai Huan River- } \\
\text { crossing tunnel in Ningbo } \\
{[27]}\end{array}$ & FEM & $\begin{array}{l}\text { Above and both } \\
\text { sides of tunnel }\end{array}$ & $\begin{array}{l}\text { Horizontal displacement, } 11.9 \\
\text { mm, settlement, } 32.6 \mathrm{~mm}\end{array}$ & $\begin{array}{l}\text { Backfill soil, silty clay, clayey silt } \\
\text { and others }\end{array}$ \\
\hline $\begin{array}{l}\text { Renmin Road River-crossing } \\
\text { tunnel in Shanghai [19] }\end{array}$ & FEM & $\begin{array}{l}\text { Directly above } \\
\text { tunnel }\end{array}$ & Settlement, $14.3 \mathrm{~mm}$ & Silty clay \\
\hline
\end{tabular}


The data in Table 1 show that settlement of the tunnels in all four projects was present. Besides, apart from the fourth case, in which the safety limit (the maximum allowable displacement of the structure, namely, $20 \mathrm{~mm} \mathrm{[29])} \mathrm{was} \mathrm{not}$ reached, the settlement of the other three projects reached or even went over the safety limit. These data validated the analysis of the mechanism of tunnel vertical displacement presented in this study.

Table 1 shows the third project. Sand was piled on both east and west sides above the center line of the tunnel. The line on the east was larger than that on the west. The results of the FEM simulation showed that the maximum horizontal displacement of the tunnel was $11.9 \mathrm{~mm}$ (toward the west) if the only east side took the load, and $7.7 \mathrm{~mm}$ (toward the east) if only the west side took the load. The horizontal displacement was $4.3 \mathrm{~mm}$ (toward the west) if both sides took the load. These simulation results validated the analysis of the mechanism of tunnel horizontal displacement presented in this study.

\subsection{Analysis of theoretical calculation results}

According to the method described in Section 3.2, the following conclusions are made using the modified load distribution model. The examples were combined and calculated to analyze the standard conditions and groundheaped loading.

Fig. 8a shows the lining bending moment diagram. The difference between the cases with and without groundheaped load gradually decreases from $0^{\circ}$ to $45^{\circ}$, whereas it gradually increases from $45^{\circ}$ to $90^{\circ}$, decreases again from $90^{\circ}$ to $135^{\circ}$, and increases from $135^{\circ}$ to $180^{\circ}$. Under groundheaped load, the positive bending moment reaches a maximum of $195.40 \mathrm{kN} \cdot \mathrm{m}$ at $0^{\circ}$ position (a $67.85 \%$ increase compared with the no-load case), whereas the negative bending moment reaches a maximum of $-180.85 \mathrm{kN} \cdot \mathrm{m}$ at $90^{\circ}$ (a 70.82\% increase). The difference increases by $69.34 \%$ on average.

Fig. 8b shows the lining axial force diagram. With and without ground-heaped load, the lining axial forces are in compression forces, although they are larger in the presence of ground-heaped load. Under ground-heaped load, the axial force reaches a maximum of $804.21 \mathrm{kN}$ at $140^{\circ}$ (an increase of $49.70 \%$ compared with the no-load case) and a minimum of $470.79 \mathrm{kN}$ at $0^{\circ}$ (a $54.09 \%$ increase).

Fig. 8c shows the lining shear diagram. Shear forces are 0 at $0^{\circ}$ and $180^{\circ}$ with and without ground-heaped load, respectively. Under ground-heaped load, shear force reaches a positive maximum of $566.78 \mathrm{kN}$ at $130^{\circ}$ point and a negative maximum of $-498.72 \mathrm{kN}$ at $40^{\circ}$. These values are, respectively, $65.66 \%$ and $68.55 \%$ larger than those in the absence of ground-heaped load.

Fig. 8 shows that the bending moment and axial and shear forces are all larger in the presence of ground-heaped load. Bending moment is at $69.34 \%$, axial force at $51.90 \%$, and shear force at $67.11 \%$.

The analysis of the effects of ground-heaped load on a tunnel shows that the confining pressure (load) in the vertical direction increased. Significant increases in the overall forces on the tunnel lining: bending moment, and axial and shear forces are present. This leads to a scenario wherein the tunnel is subjected to horizontal tension and vertical compression, and therefore undergoes distortion. Risks of lining breakage and cracking and other engineering problems are also present, which can compromise the safety and durability of the tunnel. As shown in Fig. 9, the cracking tunnel lining has been reinforced by a steel loop.

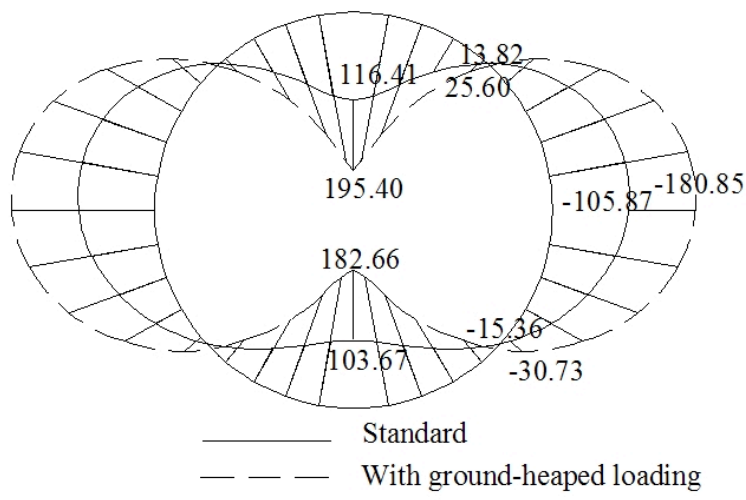

(a) Comparison of bending moments $(\mathrm{kN} \cdot \mathrm{m})$

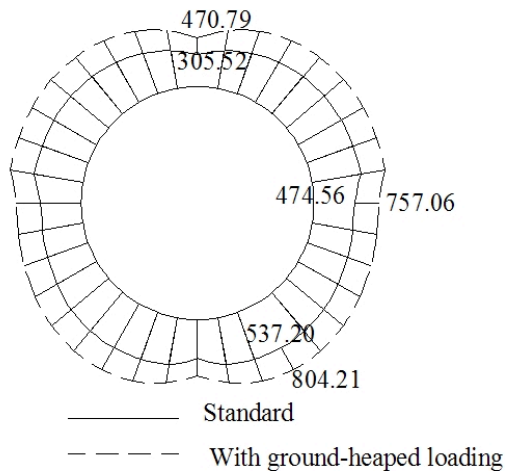

(b) Comparison of axial forces $(\mathrm{kN})$

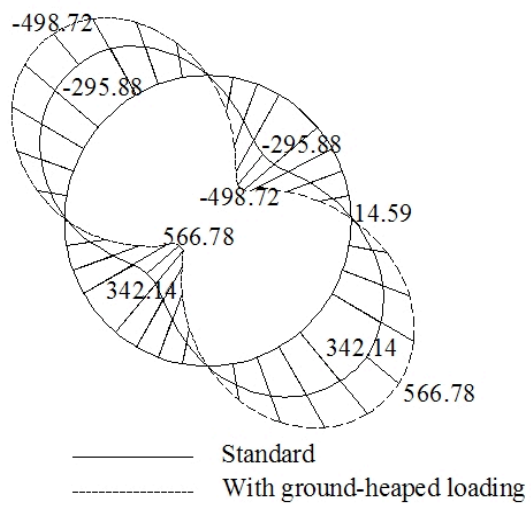

(c) Comparison of shear forces $(\mathrm{kN})$

Fig. 8. Forces on tunnel lining

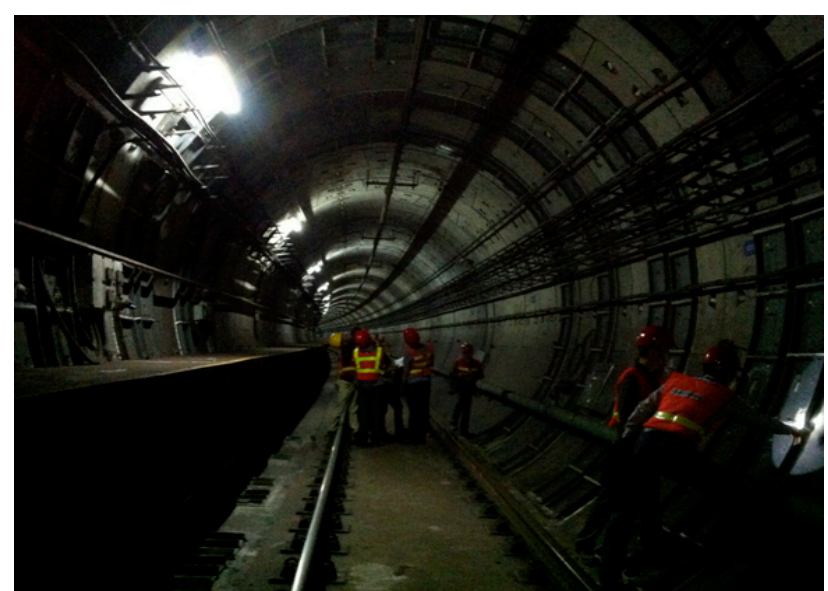

Fig. 9. Shield tunnel reinforced by full-ring steel loops 


\subsection{Analysis of the results of the three-dimensional finite element simulation}

According to Section 3.3, the results of the analysis of the deformation of the tunnel according to the finite element modeling of the standard condition and changes in magnitude of loading and load position are as follows.

Figs. 10 and 11 respectively show the schematic isometric and left side views after the settlement and deformation of the tunnel due to the impact of the standard conditions of ground-heaped loading. Uneven settlement of the tunnel occurs under the influence of symmetric loading from above, thereby exhibiting a symmetric normal distribution that is highest in the middle and decreases along both sides.

The upper and lower points of intersection between the vertical central axis and cross-section of the tunnel lining are selected as the calculated points. Vertical deflections are obtained and their mean value was taken as the settlement of the tunnel. Fig. 12 shows the results, wherein, (as in other figures), positive values mean that the tunnel is displaced upward. As can be seen, the greatest amount of settlement occurs in the middle of the tunnel, with a maximum value of $28.76 \mathrm{~mm}$ (below zero). Bumps are present at both ends, the highest of which is $2.54 \mathrm{~mm}$ (above zero). This curve is axially symmetric. Settlement of the tunnel ranges from $50 \mathrm{~m}$ to $50 \mathrm{~m}$, which is about five times the length of the ground-heaped load.

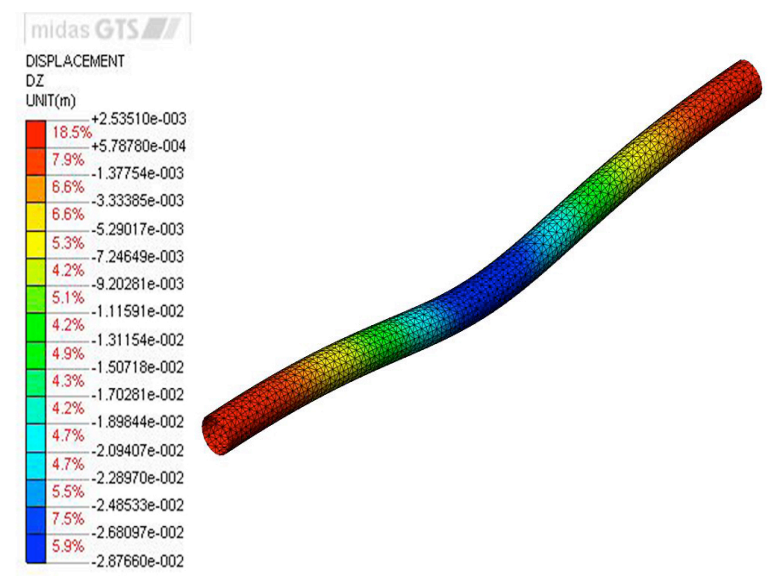

Fig. 10. Isometric side view of tunnel settlement

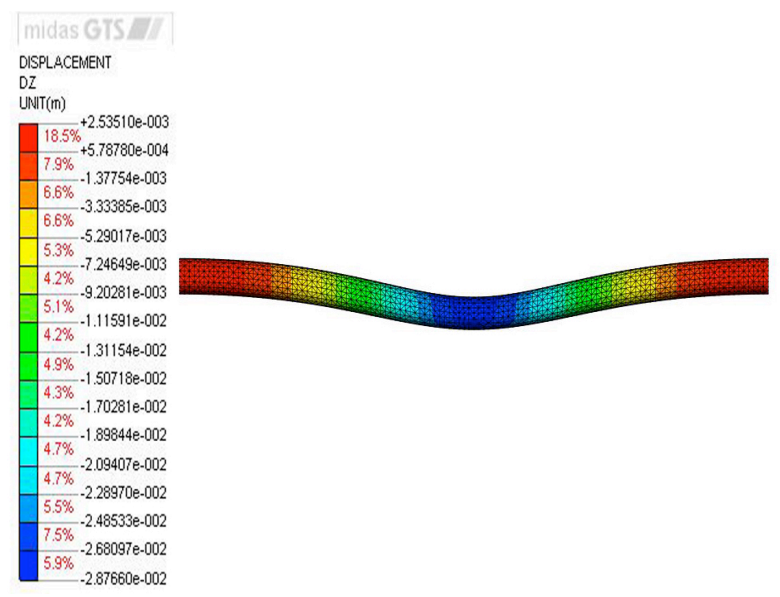

Fig. 11. Left side view of tunnel settlement

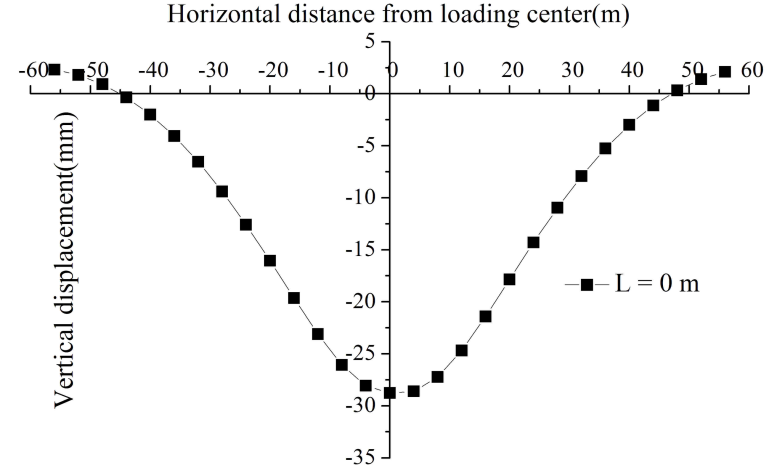

Fig. 12. Tunnel settlement curve

To study the impact of different loading magnitudes on tunnel deformation, starting with the standard condition, the surface load value $P$ is varied through a range of increasing values: $P=20,40,60,80,100,120$, and $140 \mathrm{kN} / \mathrm{m}^{2}$.

Fig. 13a compares differential vertical settlement curves obtained under various tunnel operating conditions. As demonstrated in this figure, loading $P$ increases as tunnel settlement increases. Settlement changes in the middle of the tunnel are more obvious than those at both ends. This finding is consistent with the conclusion of $\mathrm{Wu}$ Qing [19], wherein the heavier the loading, the greater the tunnel deformation. The largest additional vertical displacement of the tunnel vaults is directly under the load.

Fig. 13b shows the changes in the maximum settlement at the center point of the tunnel as $P$ varies. Maximum settlement at the center point increases almost linearly.

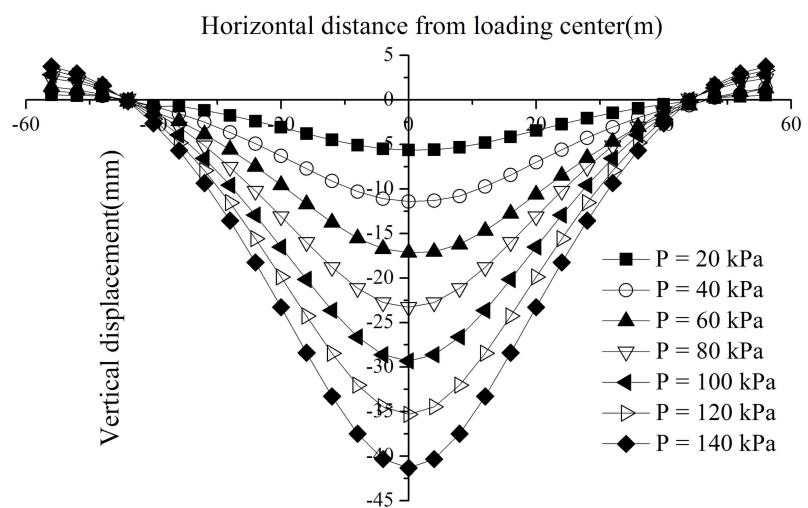

(a) Comparison of displacement curves

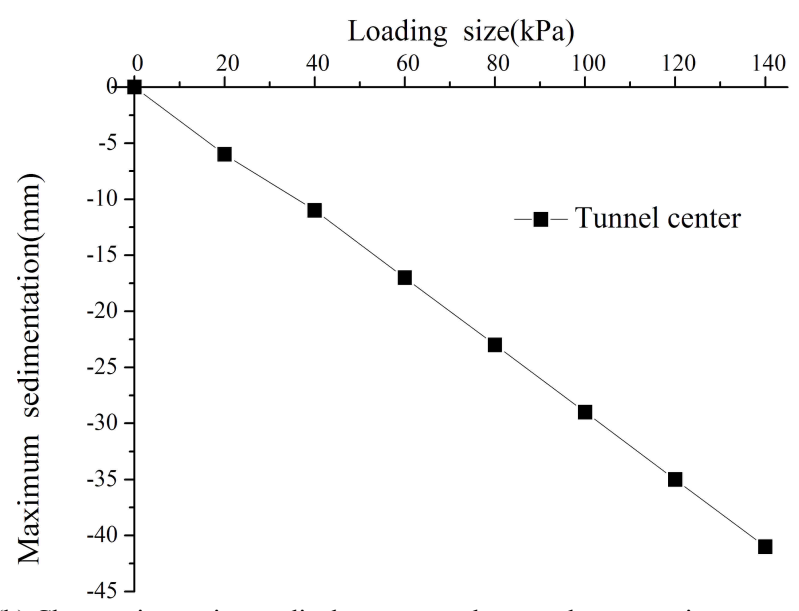

(b) Changes in maximum displacement at the tunnel center point

Fig. 13. Impact of load magnitude on tunnel settlement 
To investigate the influence of changes in loading position on tunnel deformation, loading $P=100 \mathrm{kPa}$ and area are kept constant while the horizontal distance $L$ from the center of the load to the center of the tunnel is varied through a range of increasing values: $L=0,5,10,15$, and $20 \mathrm{~m}$.

Fig. 14a shows changes in vertical displacement of the tunnel under various conditions. On the one hand, with increased $L$, tunnel settlement gradually decreases. On the other hand, the settlement in the middle of tunnel significantly changes, however, only slight changes of settlement occur at the ends of the tunnel. The scope of the tunnel deformation is essentially the same.

Fig. 14b shows the changes in the maximum settlement at the center point of the tunnel as $L$ varies. When $L=0 \mathrm{~m}$, the settlement of the tunnel is $-29.31 \mathrm{~mm}$, whereas when $L$ $=20 \mathrm{~m}$, the settlement is $-11.13 \mathrm{~mm}$. A reduction of 18.18 $\mathrm{mm}$ occurs from that of the former. The rationale is that with the load position shift, impact of the additional loading force gradually decreases in the vertical direction in the tunnel, which is reduced in tunnel settlement.

The right and left points of intersection between the horizontal central axis and the cross-section of the tunnel lining are selected as calculated points. Their mean value of horizontal deflections is used as the horizontal displacement of the tunnel.

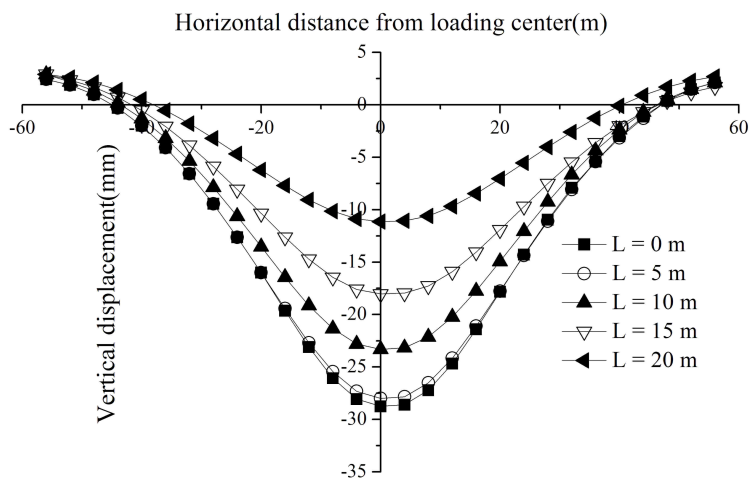

(a) Comparison of displacement curves

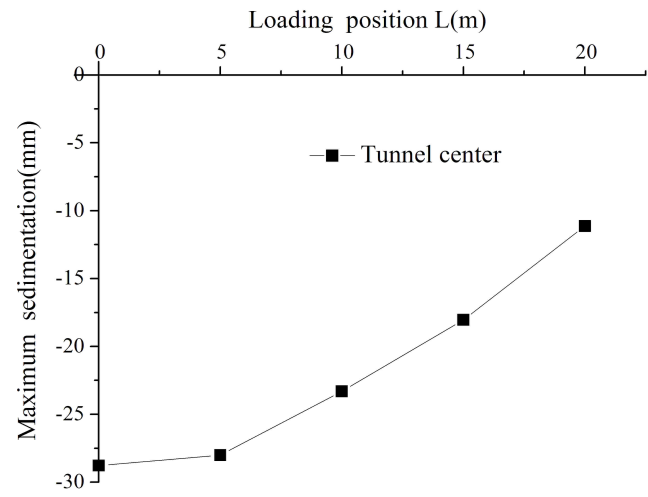

(b) Maximum displacement at the tunnel center

Fig. 14. Impact of load position on tunnel vertical displacement

Fig. 15a shows the horizontal displacements of the tunnel. Fig. 15b shows the changes in the maximum horizontal displacement at the center point of the tunnel as $L$ varies. Fig. $15 \mathrm{c}$ shows that the maximum horizontal displacement at both ends of the tunnel as $L$ varies. Positive values indicate that the tunnel moved away from the load. Fig. 15 presents the following: (1) when $L=0 \mathrm{~m}$, the maximum horizontal displacement of the tunnel approaches
0 ; (2) when $L=5 \mathrm{~m}$, the maximum horizontal displacement of the tunnel abruptly increases, thereby presenting a symmetric normal distribution; (3) when $L=10 \mathrm{~m}$, the horizontal displacement at the center of the tunnel is at its peak; (4) as $L$ continues to increase, the horizontal displacement at the center of the tunnel starts to decrease, while the horizontal displacements at both ends continue to increase; and (5) the horizontal displacements at both ends of the tunnel gradually increase as $L$ becomes larger.

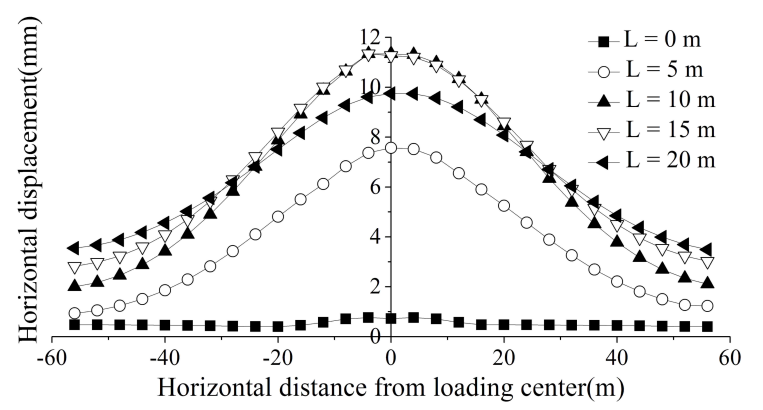

(a) Comparison of displacement curves

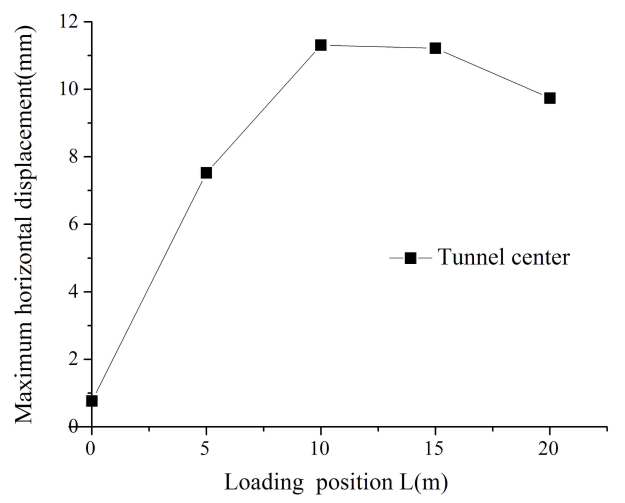

(b) Maximum displacement at the tunnel center

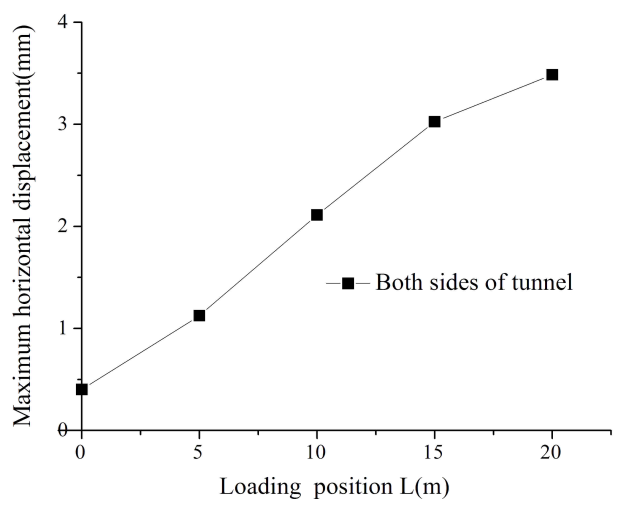

(c) Maximum displacement on both sides of the tunnel

Fig. 15. Comparison of tunnel horizontal displacement curves

When loading is directly above the tunnel, the pressure of the tunnel in the horizontal direction reaches balance. Thus, horizontal displacement is small. However, when the loading deviates to either side, the horizontal forces are no longer mutually offsetting and balanced. This imbalance leads to an additional force in the horizontal direction. When the deviation reaches a certain value, the additional force reaches its peak. After which, with further deviation of the loading, the additional force decreases, so that the stress gradually returns to its previously balanced state. 


\section{Conclusions}

To explore the force and deformation laws of existing tunnels caused by ground-heaped load, the effect of groundheaped load on tunnels was studied. Based on the modified routine method of lining design theory and threedimensional finite element model, the internal forces of the lining and deformation laws of existing tunnels were studied with and without ground-heaped load, respectively. The conclusions are drawn as follows:

(1) Ground-heaped load breaks the existing force balance in a shield tunnel, thereby creating an additional downward force that causes the tunnel to sink and aggravating horizontal stretching and vertical compression. Horizontal displacement of the tunnel would occur with an asymmetric loading.

(2) Under ground load, the bending moment and axial and shear forces on the tunnel lining are greater than those in the absence of such load, leading to an excessive total load on the lining. The effects of ground-heaped loading can lead to significant risks to the safety and durability of the tunnel. Therefore, overlarge ground-heaped loading should be prevented when a tunnel is in operation.

(3) Under the influence of ground-heaped loading, differential settlement of the tunnel occurs in the vertical direction. This displacement exhibits a normal distribution, with the highest value in the middle and the lowest on each side. As loading $P$ increases, the maximum settlement of the tunnel increases almost linearly. As the horizontal distance $L$ between the load and the tunnel increases, the settlement at the center point of the tunnel gradually decreases, with smaller changes at both ends. Horizontal displacement at the center of the tunnel increases from zero to a peak value. The value decreases after the peak, although the horizontal displacements on each side continue to increase.

This study analyzes the laws of force and deformation of the shield tunnel under ground-heaped load through theoretical calculation and three-dimensional finite element modeling. However, the finite element simulation model is simple. Many factors, such as grouting layers, different depths, and different types of shields, may influence the force and deformation of shield tunnels caused by ground loads. These factors will be the focus of future research.

\section{Acknowledgements}

This work was financially supported by public technology projects of Science Technology Department of Zhejiang Province (NO: 2016C33051) and science and technology project plan of Ministry of Housing and Urban-Rural Development of the People's Republic of China in 2015 (NO: 2015-K5-026).

This is an Open Access article distributed under the terms of the Creative Commons Attribution Licence

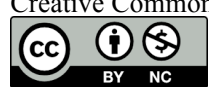

\section{References}

1. Zhang, J. F., Chen, J. J., Wang, J. H., Zhu, Y. F., "Prediction of tunnel displacement induced by adjacent excavation in soft soil". Tunnelling and Underground Space Technology, 36(6), 2013, pp. 24-33.

2. Zhang, Z. G., Huang, M. S., Wang, W. D., "Evaluation of deformation response for adjacent tunnels due to soil unloading in excavation engineering". Tunnelling and Underground Space Technology, 38(9), 2013, pp. 244-253.

3. Yu, X. L., Jia, B. Y., "Analysis of excavating foundation pit to nearby bridge foundation". Procedia Earth and Planetary Science, (5), 2012, pp. 102-106.

4. Klar, A., Vorster, T. E. B., Soga, K., Mair, R. J., "Soil-pipe interaction due to tunnelling: comparison between winkler and elastic continuum solutions". Geotechnique, 55(6), 2005, pp. 461466.

5. Xu, M., Shi, L., "A Numerical Study on the effect of tunneling on adjacent buried pipelines". Proceedings of the International Conference on Pipelines and Trenchless Technology, ASCE, 2011, pp. 1376-1387.

6. Giovanni, B., "Full-face excavation of large tunnels in difficult conditions". Journal of Rock Mechanics and Geotechnical Engineering, 8(3), 2016, pp. 294-303.

7. Schroeder, F. C., Potts, D. M., Addenbrooke, T. I., "The influence of pile group loading on existing tunnels". Geotechnique, 54(6), 2004, pp. 351-362.

8. Francesco, B., "Effect of tunnelling on pile foundations". Soils and Foundations, 54(3), 2014, pp. 280-295.

9. Yao, A. J., Yang, X. J., Dong, L., "Numerical analysis of the influence of isolation piles in metro tunnel construction of adjacent buildings". Procedia Earth and Planetary Science, 5, 2012, pp. $150-154$.

10. Richards, J. A., "Inspection, maintenance and repair of tunnels: international lessons and practice". Tunnelling and Underground Space Technology, 13(4), 1998, pp. 369-375.

11. Cavalaro, S. H. P., Blom, C. B. M., Walraven, J. C., Aguado, A., "Structural analysis of contact deficiencies in segmented lining". Tunnelling and Underground Space Technology, 26(6), 2011, pp. 734-749.
12. Yuan, Y., Bai, Y., Liu, J., "Assessment service state of tunnel structure". Tunnelling and Underground Space Technology, 27(1), 2012, pp. 72-85.

13. Zhang, X. M., Ou, X. F., Yang, J. S., Fu, J. Y., "Deformation response of an existing tunnel to upper excavation of foundation pit and associated dewatering". International Journal of Geomechanics, 17(4), 2017, pp. 04016112.

14. Chang, C. T., Sun, C. W., Duann, S. W., Hwang, R. N., "Response of a Taipei rapid transit system (TRTS) tunnel to adjacent excavation". Tunnelling and Underground Space Technology, 16(3), 2001, pp. 151-158.

15. Huang, X., Schweiger, H. F., Huang, H. W., "Influence of deep excavations on nearby existing tunnels". International Journal of Geomechanics, 13(2), 2013, pp. 170-180.

16. Abdel-Meguid, M., Rowe, R. K., Lo, K. Y., "3D effects of surface construction over existing subway tunnels". International Journal of Geomechanics, 2(4), 2002, pp. 447-469.

17. Zheng, G., Wei, S. W., "Numerical analyses of influence of overlying pit excavation on existing tunnels". Journal of Central South University of Technology, 15(S2), 2008, pp. 69-75.

18. Li, C. L., Wang, G. Q., Zhao, K. J., Zhu, C. F., "Vertical mechanical behavior on shield tunnel under loads on ground surface". Journal of Jilin University (Engineering and Technology Edition), 41(2), 2011, pp. 180-184.

19. Wu, Q., "Research on influence of shield tunnel structure on ground heaped road". Master thesis of Shanghai Jiao Tong University, China, 2012, pp. 6-15.

20. Katebi, H., Rezaei, A. H., Hajialilue-Bonab, M., Tarifard, A., "Assessment the influence of ground stratification, tunnel and surface buildings specifications on shield tunnel lining loads (by FEM)". Tunnelling and Underground Space Technology, 49, 2015, pp. 67-78.

21. Zhang, X. Y., Zhan, Y., "Settlement analysis of subway tunnel under overload". Journal of Huangshi Institute of Technology, 27(3), 2011, pp. 37-40.

22. Yamamoto, K., Lyamin, A. V., Wilson, D. W., Sloan, S. W., Abbo, A. J., "Stability of a circular tunnel in cohesive-frictional soil subjected to surcharge loading". Computers and Geotechnics, 38, 2011, pp. 504-514. 
23. Yamamoto, K., Lyamin, A. V., Wilson, D. W., Sloan, S. W., Abbo, A. J., "Stability of dual circular tunnels in cohesive-frictional soil subjected to surcharge loading". Computers and Geotechnics, 50, 2013, pp. 41-54.

24. Yang, Y. B., Xie, X. Y., Wang, R. L., "Numerical simulation of dynamic response of operating metro tunnel induced by ground explosion". Journal of Rock Mechanics and Geotechnical Engineering, 2(4), 2010, pp. 373-384.

25. Atkinson, J. H., Potts, D. M., "Stability of a shallow circular tunnel in cohesionless soil". Geotechnique, 27(2), 1977, pp. 203-215.

26. Wu, Q., Du, S. J., "Model test on influence of ground heaped load on existing shield tunnel structure". Chinese Journal of Underground Space and Engineering, 10(1), 2014, pp. 57-66.

27. Qin, H., Shi, G., "Study on effect of construction loads on immersed tunnel buried section". Low Temperature Architecture Technology, (10), 2013, pp. 111-113.

28. Huang, H. W., Zhang, D. M., "Resilience analysis of shield tunnel lining under extreme surcharge: Characterization and field application". Tunneling and Underground Space Technology, 51, 2016, pp. 301-312.
29. Shanghai Municipal Engineering Administration Bureau., "Shanghai municipal law (94) No.854: temporary provisions of subway protection management of Shanghai construction on land along subway". Shanghai: Shanghai Municipal Engineering Administration Bureau (Notification), China, 1994, pp. 3-4.

30. Working Group No.2., International Tunneling Association, "Guidelines for the design of shield tunnel lining". Tunnelling and Underground Space Technology, 15(3), 2000, pp. 303-331.

31. Wei, G., Hong, J., Wei, X. J., "Mechanical analysis of segment floating during shield tunnel construction". Chinese Journal of Rock Mechanics and Engineering, 31(6), 2012, pp. 1257-1263.

32. Zhang, F. X., Fu, D. M., Yang, G. X., Xiang, Z. C., "Shield tunnel construction manual". Beijing: China Communications Press, China, 2005, pp. 210-214.

33. Xu, Z. F., Wang, Y. Y., Dong, Y. P., Huang, X. C., "Influence on large shield construction disturbance displacement". Traffic Construction and Management, (5), 2010, pp. 170-180.

34. Wang, Q., "Analysis of influence on shield tunnel by excessive ground load and structural safety". Urban Construction Theory Research, (12), 2013, pp. 1-7. 